\title{
ANALISA KESTABILAN SISTEM KENDALI EKSITASI GENERATOR TIPE ARUS SEARAH TANPA DAN DENGAN PENGENDALI BERDASARKAN PENDEKATAN TANGGAPAN FREKUENSI
}

\author{
Heru Dibyo Laksono ${ }^{(1)^{*}}$, Mazues ${ }^{(2)}$, Wayu Diafridho A ${ }^{(3)}$ \\ ${ }^{(1,2)}$ Jurusan Teknik Elektro Fakultas Teknik Universitas Andalas \\ (3) PT. PLN (Persero) Area Padang Sidempuan Sumatera Utara \\ *Corresponding author, e-mail : heru_dl@ft.unand.ac.id
}

\begin{abstract}
Abstrak - Jurnal ini membahas tentang analisa kestabilan sistem kendali eksitasi generator tipe arus searah tanpa dan dengan pengendali. Analisa kestabilan yang dilakukan meliputi analisa kestabilan mutlak, analisa kestabilan relatif dan analisa kestabilan internal. Untuk analisa kestabilan mutlak ditunjukkan dengan menggunakan nilai margin penguatan dan nilai margin fasa. agar performansi sistem memuaskan maka diusahakan nilai margin penguatan ini besar dari $6 \mathrm{~dB}$ dan nilai margin fasa berkisar antara $30^{\circ}$ sampai $60^{\circ}$. Untuk kestabilan relatif ditunjukkan dengan nilai puncak resonansi. Sistem akan bersifat stabil relatif jika nilai puncak resonansi berkisar antara $1.10 \mathrm{~s} / \mathrm{d}$ 1.50. sistem akan bersifat stabil internal jika semua fungsi alih lingkar tertutup dari masukan ke keluaran internal bersifat stabil. Untuk indikator kestabilan internal ini ditunjukkan oleh angka 0 jika sistem bersifat stabil internal dan angka 1 jika sistem bersifat tidak stabil internal. Untuk pengendali yang digunakan terdiri dari pengendali Proporsional (P), pengendali Proporsional Integral (PI), pengendali Proporsional Diferensial (PD) dan pengendali Proporsional Integral Diferensial (PID). Pengendali - pengendali tersebut dirancang dengan pendekatan tanggapan frekuensi. Hasil yang diperoleh bahwa tanggapan tegangan sistem eksitasi generator tipe arus searah dengan pengendali Proporsional (P), pengendali Proporsional Integral (PI), pengendali Proporsional Diferensial (PD) dan pengendali Proporsional Integral Diferensial (PID) bersifat stabil mutlak, stabil relatif dan stabil internal.
\end{abstract}

Kata kunci : sistem eksitasi, kestabilan mutlak, kestabilan relatif, kestabilan internal, tanggapan frekuensi

\begin{abstract}
This journal discussed the stability analysis of generator excitation control system in type of direct current without and by using controller. The stability Analysis was conducted on absolute stability analysis, relative stability analysis and internal stability analysis. For the absolute stability analysis was demonstrated by using gain margin and phase margin value. In order to get satisfied system performance so that cultivated gain margin value was greater than $6 \mathrm{~dB}$ and phase margin value was in ranges from $30^{\circ}$ to $60^{\circ}$. For the relative stability was shown by the peak value of resonance. The system would be relatively stable if the peak value of resonance range was between 1:10 to 1:50. The system would be internal stable if all closed circle transfer functions from input to internal output was stable. For internal stability indicator was shown by number 0 if the system is internally stable and number 1 if the system was internally unstable. For controllers used consisted of Proportional controller (P), Proportional Integral controller (PI), Proportional Differential controller (PD) and Proportional Integral Differential controller (PID). The controllers were designed with a frequency response approach. The results showed that the voltage response of generator excitation system type direct current with Proportional controller (P), Proportional Integral controller (PI), Proportional Differential controller (PD) and Proportional Integral Differential controller (PID) was stable of absolute, relative and internal.
\end{abstract}

Keyword: Excitation system, absolute stability, relative stability, internal stability, frequency response

Copyright $\subset 2016$ JNTE. All rights reserved

\section{PENDAHULUAN}

Sistem eksitasi adalah suatu peralatan yang bertugas menjaga tanggapan tegangan dan daya reaktif generator agar tetap stabil dan kokoh pada pada titik operasi yang diinginkan. Suatu kenaikan daya reaktif pada sisi beban akan mengakibatkan penurunan magnitude tegangan terminal. Penurunan magnitude tegangan terminal ini kemudian akan disensor oleh suatu potensial transformator. Selanjutnya tegangan terminal akan disearahkan dan dibandingkan 
dengan suatu titik nilai acuan. Pengatur sinyal kesalahan penguat akan mengatur tegangan eksitasi sehingga tegangan eksitasi generator akan meningkat. Jika tegangan eksitasi meningkat maka daya tegangan yang dibangkitkan oleh generator akan meningkat pula [1]. Dalam sistem tenaga listrik, tanggapan tegangan sistem eksitasi merupakan hal yang sangat penting untuk diperhatikan karena dapat mempengaruhi kestabilan dan kekokohan tegangan sistem tenaga listrik. Ketidakstabilan dan ketidakkokohan tanggapan tegangan akan menyebabkan sistem tenaga listrik secara keseluruhan akan mengurangi keandalan, terutama kualitas dan kemampuan pemindahan daya dari pembangkit ke konsumen, kondisi terparah terjadinya mekanisme load shedding [2].

Dalam sistem interkoneksi skala besar, alat penstabil tegangan manual tidak pernah dipakai dan sebagai gantinya dipasang sebuah peralatan penstabil tegangan otomatis yang dinamakan Automatic Voltage Regulator (AVR) disetiap generator. Faktor-faktor yang mempengaruhi tanggapan tegangan antara lain kenaikan pembebanan saluran transmisi, gangguan pengaturan daya reaktif, dinamika OLTC (on load tap changer) trafo dan karakteristik beban. Tanggapan tegangan sistem tenaga listrik ditentukan oleh tanggapan tegangan yang dilakukan oleh sistem eksitasi yang terdapat dalam generator dan beberapa rangkaian pengendali lain yang terintegrasi satu sama lain [3].

Sebuah sistem eksitasi generator dikatakan tidak stabil jika tanggapannya terhadap suatu masukan menghasilkan osilasi yang keras atau bergetar pada suatu amplitudo tertentu. Sebaliknya suatu sistem eksitasi generator disebut stabil jika sistem tersebut akan tetap dalam keadaan diam atau berhenti kecuali jika dirangsang (dieksitasi oleh suatu fungsi masukan dan akan kembali dalam keadaan diam jika eksitasi tersebut dihilangkan).

Beberapa penelitian yang sudah dilakukan yang berkaitan dengan tanggapan tegangan sistem eksitasi ini diantaranya tanggapan tegangan sistem eksitasi dengan metoda Proporsional Integral Diferensial (PID) [4], metoda Algoritma genetika [5] dan metoda $\mathrm{H} \sim$ [6]. Pada beberapa penelitian yang sudah dilakukan tersebut, diperoleh informasi bahwa kestabilan tanggapan tegangan sistem eksitasi generator tipe arus searah dititik operasinya kurang begitu memuaskan terutama untuk kestabilan mutlak, relatif dan internal. terutama untuk sistem eksitasi generator tipe arus searah.

Untuk dengan menggunakan bantuan perangkat lunak Matlab dilakukan analisa kestabilan tanggapan tegangan sistem eksitasi generator tipe arus searah. Analisa ketabilan tanggapan tegangan sistem eksitasi arus searah ini dilakukan tanpa dan dengan menggunakan berbagai pengendali. Adapun jenis pengendali yang digunakan pengendali Proporsional (P), pengendali Proporsional Integral (PI), pengendali Proporsional Diferensial (PD) dan pengendali Proporsional Integral Diferensial (PID). Pengendali - pengendali ini dirancang berdasarkan pendekatan tanggapan frekuensi sedangkan analisa kestabilan yang dilakukan meliputi analisa kestabilan mutlak, kestabilan relatif dan kestabilan internal.

Dengan adanya penelitian ini diharapkan nantinya diperoleh informasi kestabilan mutlak, kestabilan relatif dan kestabilan internal dari tanggapan tegangan sistem eksitasi generator tipe arus searah. Agar tercapai hasil penelitian yang diinginkan maka penelitian ini dibatasi sebagai berikut

1. Model sistem eksitasi generator bersifat linier, tak berubah terhadap waktu dan kontinu.

2. Sistem eksitasi generator tipe arus searah bersifat satu masukan dan satu keluaran

3. Analisa dilakukan dengan bantuan perangkat lunak Matlab

\section{TINJAUAN PUSTAKA}

Pada bagian ini menjelaskan tentang pemodelan sistem eksitasi generator, perancangan pengendali dan analisa kestabilan. Untuk pemodelan matematis sistem eksitasi generator meliputi pemodelan amplifier, pemodelan eksiter, pemodelan generator dan pemodelan sensor. Untuk pemodelan matematis amplifier dinyatakan dalam bentuk persamaan (1) berikut[7-8]

$$
\mathrm{G}_{\mathrm{a}}(\mathrm{s})=\frac{\mathrm{K}_{\mathrm{A}}}{1+\tau_{\mathrm{A}} \mathrm{s}}
$$

Hasil pemodelan matematis amplifier berupa fungsi alih orde satu dengan 2 parameter yaitu konstanta penguatan amplifier dan konstanta waktu amplifier. Nilai konstanta penguatan 
amplifier memiliki rentang nilai dari 10.0000 sampai 40.000 sedangkan nilai konstanta waktu amplifier memiliki rentang nilai dari 0.0200 detik sampai 0.1000 detik. Untuk pemodelan matematis eksiter dinyatakan dalam bentuk persamaan (2) berikut [7][8]

$$
\mathrm{G}_{\mathrm{e}}(\mathrm{s})=\frac{\mathrm{K}_{\mathrm{E}}}{1+\tau_{\mathrm{E}} \mathrm{s}}
$$

Hasil pemodelan matematis eksiter ini berupa fungsi alih orde satu dengan 2 parameter yaitu konstanta penguatan eksiter dan konstanta waktu eksiter. Nilai konstanta penguatan eksiter ini memiliki rentang nilai dari 1.0000 sampai 10.0000 dan nilai konstanta waktu eksiter memiliki rentang nilai dari 0.4000 sampai 1.0000. Untuk pemodelan matematis generator dinyatakan dalam bentuk persamaan (3) berikut [7][8]

$$
\mathrm{G}_{\mathrm{G}}(\mathrm{s})=\frac{\mathrm{K}_{\mathrm{G}}}{1+\tau_{\mathrm{G}} \mathrm{S}}
$$

Hasil pemodelan matematis generator ini berupa fungsi alih orde satu dengan 2 parameter yaitu konstanta penguatan generator dan konstanta waktu generator. Nilai konstanta penguatan generator memiliki rentang nilai dari 0.7000 sampai 1.0000 sedangkan nilai konstanta waktu generator memiliki nilai rentang nilai dari 1.0000 detik sampai 2.0000 detik pada keadaan beban nol sampai keadaan beban penuh. Untuk pemodelan matematis sensor dinyatakan dalam bentuk persamaan (4) berikut [7][8]

$$
\mathrm{H}_{\mathrm{s}}(\mathrm{s})=\frac{\mathrm{K}_{\mathrm{s}}}{\mathrm{T}_{\mathrm{s}} \mathrm{s}+1}
$$

Hasil pemodelan matematis sensor ini berupa fungsi alih orde satu dengan 2 parameter yaitu konstanta penguatan sensor dan konstanta waktu sensor. Adapun nilai konstanta penguatan sensor memiliki rentang nilai dari 0.9000 sampai 1.1000 sedangkan nilai konstanta waktu sensor memiliki rentang nilai dari 0.0010 detik sampai 0.0600 detik. Selanjutnya komponen komponen sistem eksitasi generator ini digabungkan dan terbentuk diagram blok dari sistem eksitasi generator yang diperlihatkan pada Gambar 1. Berdasarkan diagram blok pada Gambar 1. kemudian diperoleh fungsi alih lingkar terbuka dan fungsi alih lingkar tertutup dari sistem eksitasi generator. Untuk fungsi alih lingkar terbuka diperlihatkan pada persamaan
(4) dan fungsi alih lingkar tertutup diperlihatkan pada persamaan (5) berikut

$$
\begin{aligned}
& G(s) H(s)=G_{a}(s) G_{e}(s) G_{G}(s) H(s) \\
& \frac{V_{t}(s)}{V_{\text {ref }}(s)}=\frac{G_{a}(s) G_{e}(s) G_{G}(s)}{1+G_{a}(s) G_{e}(s) G_{G}(s) H(s)}
\end{aligned}
$$

Pengendali yang digunakan diantaranya pengendali Proporsional (P), pengendali Proporsional Integral (PI), pengendali Proporsional Diferensial (PD) dan pengendali Proporsional Integral Diferensial (PID). Pengendali - pengendali tersebut dirancang dengan metoda tanggapan frekuensi. Untuk fungsi alih pengendali Proporsional (P) diperlihatkan pada persamaan (7) berikut [9]

$$
\mathrm{C}(\mathrm{s})=\mathrm{K}_{\mathrm{p}}
$$

Untuk fungsi alih pengendali Proporsional Integral (PI) diperlihatkan pada persamaan (8) berikut [9]

$$
\mathrm{C}(\mathrm{s})=\mathrm{K}_{\mathrm{p}}+\frac{\mathrm{K}_{\mathrm{i}}}{\mathrm{s}}
$$

Fungsi alih pengendali Proporsional Diferensial (PD) diperlihatkan pada persamaan (9) berikut [9]

$$
\mathrm{C}(\mathrm{s})=\mathrm{K}_{\mathrm{p}}+\mathrm{K}_{\mathrm{D}} \mathrm{s}
$$

Fungsi alih pengendali Proporsional Integral Diferensial (PID) diperlihatkan pada persamaan (10) berikut [9]

$$
\mathrm{C}(\mathrm{s})=\mathrm{K}_{\mathrm{p}}+\frac{\mathrm{K}_{\mathrm{i}}}{\mathrm{s}}+\mathrm{K}_{\mathrm{D}} \mathrm{s}
$$

dimana $\mathrm{K}_{\mathrm{p}}$ adalah konstanta Proporsional, $\mathrm{K}_{\mathrm{i}}$ adalah konstanta integral dan $K_{d}$ adalah konstanta diferensial.

Untuk analisa kestabilan dilakukan terdiri dari analisa kestabilan mutlak [10], kestabilan relatif [10] dan kestabilan internal [11]. Untuk analisa kestabilan mutlak ditunjukkan dengan menggunakan nilai margin penguatan dan nilai margin fasa. Sistem akan bersifat stabil mutlak jika nilai margin penguatan dan nilai margin fasa bernilai positif. Margin penguatan adalah seberapa besar penguatan dapat dinaikkan sebelum sistem menjadi tidak stabil. Selain itu 
agar performansi sistem memuaskan maka diusahakan nilai margin penguatan ini besar dari $6 \mathrm{~dB}$ [12]. Margin fasa adalah banyaknya fasa tertinggal yang ditambahkan pada frekuensi gain crossover yang diinginkan agar sistem berbatasan dengan keadaan tidak stabil. Agar performansi sistem kendali memuaskan maka diusahakan nilai margin fasa berkisar antara $30^{\circ}$ sampai $60^{\circ}[12]$. Untuk kestabilan relatif ditunjukkan dengan nilai puncak resonansi. Nilai puncak resonansi adalah nilai magnituda tanggapan sistem lingkar tertutup pada saat terjadinya resonansi. Sistem akan bersifat stabil relatif jika nilai puncak resonansi berkisar antara $1.10 \mathrm{~s} / \mathrm{d} 1.50$ [12]. Untuk definisi kestabilan internal mengacu kepada sistem yang direpresentasikan pada Gambar 3 dimana sistem akan bersifat stabil internal jika semua fungsi alih lingkar tertutup dari masukan $(\mathrm{r}, \mathrm{d}, \mathrm{n}) \mathrm{ke}$ keluaran internal $\left(\mathrm{x}_{1}, \mathrm{x}_{2}, \mathrm{x}_{3}\right)$ bersifat stabil. Untuk indikator kestabilan internal ini ditunjukkan oleh angka 0 jika sistem bersifat stabil internal dan angka 1 jika sistem bersifat tidak stabil internal[11].

\section{METODE PENELITIAN}

Penelitian ini dimulai dengan pemodelan matematis sistem eksitasi generator. Pemodelan matematis sistem eksitasi generator yang dibahas meliputi pemodelan amplifier, pemodelan eksiter, pemodelan generator dan pemodelan sensor. Tipe sistem eksitasi generator yang digunakan adalah sistem eksitasi generator tipe arus searah bentuk diagram blok yang diperlihatkan pada Gambar 1. Selain itu pemodelan matematis sistem eksitasi generator ini dilakukan dengan menggunakan persamaan linear diferensial dan transformasi Laplace. Hasil pemodelan masing - masing komponenberupa fungsi alih orde satu yang dinyatakan dalam bentuk persaman (1) s/d (4). Dengan mensubtitusi nilai - nilai parameter pada Tabel 1. ke persamaan (1) s/d (4) diperoleh fungsi alih untuk amplifier yang dinyatakan dalam bentuk persamaan (11) berikut

$$
\mathrm{G}_{\mathrm{a}}(\mathrm{s})=\frac{10.0000}{1.0000+0.1000 \mathrm{~s}}
$$

fungsi alih untuk eksiter yang dinyatakan dalam bentuk persamaan (12) berikut

$$
\mathrm{G}_{\mathrm{e}}(\mathrm{s})=\frac{1.0000}{1.0000+0.4000 \mathrm{~s}}
$$

fungsi alih untuk generator yang dinyatakan dalam bentuk persamaan (13) berikut

$$
\mathrm{G}_{\mathrm{G}}(\mathrm{s})=\frac{1.0000}{1.0000+1.0000 \mathrm{~s}}
$$

fungsi alih untuk sensor yang dinyatakan dalam bentuk persamaan (14) berikut

$$
\mathrm{H}_{\mathrm{s}}(\mathrm{s})=\frac{1.0000}{1.0000+0.0100 \mathrm{~s}}
$$

Masing - masing komponen pada persamaan (11) s/d (14) disubstitusikan ke diagram blok pada Gambar 1. serta diperoleh fungsi alih lingkar terbuka dan fungsi alih lingkar tertutup dari sistem eksitasi generator. Untuk fungsi alih lingkar terbuka diperlihatkan pada persamaan (15) dan untuk fungsi alih lingkar tertutup diperlihatkan pada persamaan (16). Adapun keluaran dari kedua fungsi alih tersebut adalah tegangan terminal sedangkan masukannya adalah tegangan referensi. Selanjutnya dilakukan analisa kestabilan dari tanggapan tegangan sistem eksitasi tipe arus searah. Analisa kestabilan yang dilakukan terdiri dari analisa kestabilan mutlak, analisa kestabilan relatif dan analisa kestabilan internal.

Selanjutnya dilakukan perancangan pengendali untuk sistem eksitasi generator tipe arus searah. Perancangan pengendali dilakukan dengan bantuan Matlab dan dengan menggunakan pendekatan tanggapan frekuensi berdasarkan fungsi alih lingkar terbuka sistem eksitasi generator tipe arus searah yang diperlihatkan pada persamaan (15). Pengendali yang dirancang meliputi pengendali Proporsional (P), pengendali Proporsional Integral (PI), pengendali Proporsional Diferensial (PD) dan pengendali Proporsional Integral Diferensial (PID). Hasil dari perancangan pengendali ini diperolehnya fungsi alih masing - masing pengendali. Adapun bentuk fungsi alih dari masing - masing pengendali diperlihatkan pada persamaan (7) s/d (10). Selanjutnya dengan berpedoman diagram blok pada Gambar 2. maka diperoleh fungsi alih lingkar terbuka dan fungsi alih lingkar tertutup tanggapan tegangan sistem eksitasi generator tipe arus searah dengan berbagai pengendali. Selanjutnya dilakukan analisa kestabilan 
tanggapan tegangan sistem eksitasi generator terhadap dengan pengendali. Analisa kestabilan yang dilakukan sama dengan analisa kestabilan tanggapan tegangan sistem eksitasi generator tanpa pengendali

\section{HASIL DAN PEMBAHASAN}

Bagian ini menperlihatkan fungsi alih masing -masing pengendali dan analisa kestabilan tanggapan tegangan sistem eksitasi generator tipe arus searah. Analisa kestabilan yang dilakukan pada bagian ini adalah analisa kestabilan mutlak, kestabilan relatif dan kestabilan internal dari tanggapan tegangan sistem eksitasi generator.

Untuk fungsi alih pengendali Proporsional (P) dinyatakan dalam bentuk persamaan (15) berikut

$$
C(s)=0.4000
$$

Untuk fungsi alih pengendali Proporsional Integral (PI) dinyatakan dalam bentuk persamaan (16) berikut

$$
C(s)=0.3557+\frac{0.0952}{s}
$$

Untuk fungsi alih pengendali Proporsional Diferensial (PD) dinyatakan dalam bentuk persamaan (17) berikut

$$
\mathrm{C}(\mathrm{s})=1.0094+0.2449 \mathrm{~s}
$$

Untuk fungsi alih pengendali Proporsional Integral Diferensial (PID) dinyatakan dalam bentuk persamaan (18) berikut

$$
C(s)=0.9250+\frac{2.0000}{s}+0.6016 s
$$

Adapun hasil analisa kestabilan mutlak untuk tanggapan tegangan sistem eksitasi generator tipe arus serah tanpa pengendali diperlihatkan pada Tabel 2 .

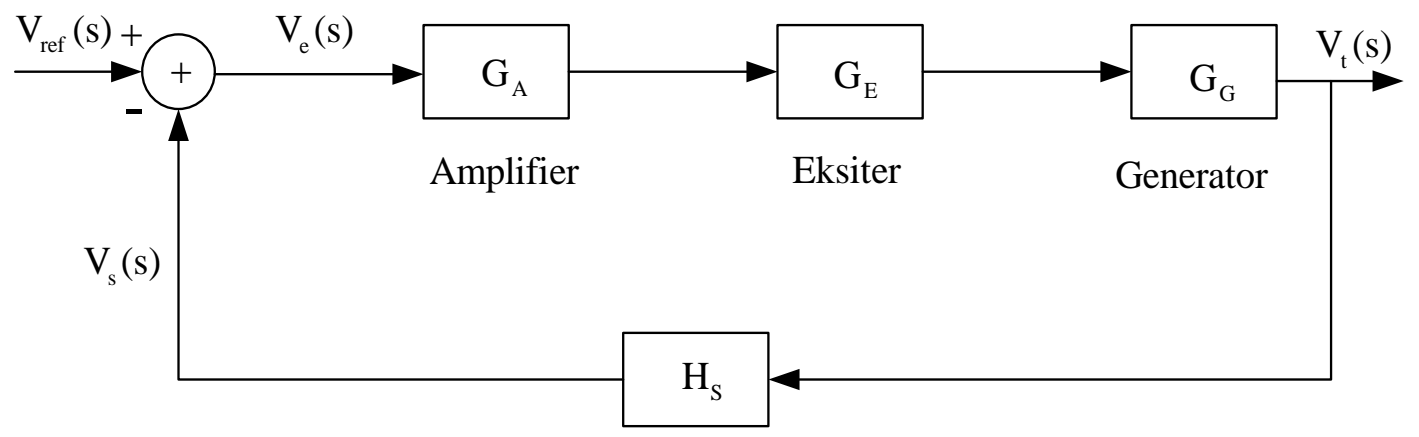

Sensor

Gambar 1. Diagram Blok Sistem Eksitasi Generator Tipe Arus Searah [10][11]

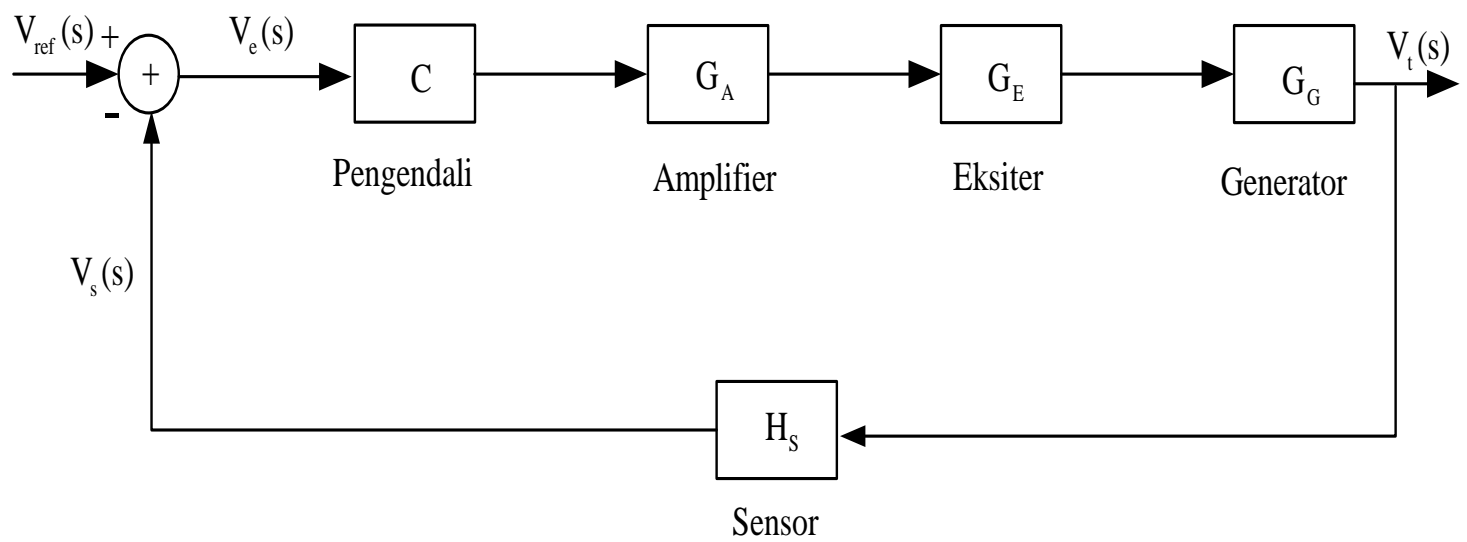

Gambar 2. Diagram Blok Sistem Eksitasi Generator Tipe Arus Searah Dengan Pengendali [10][[11] 


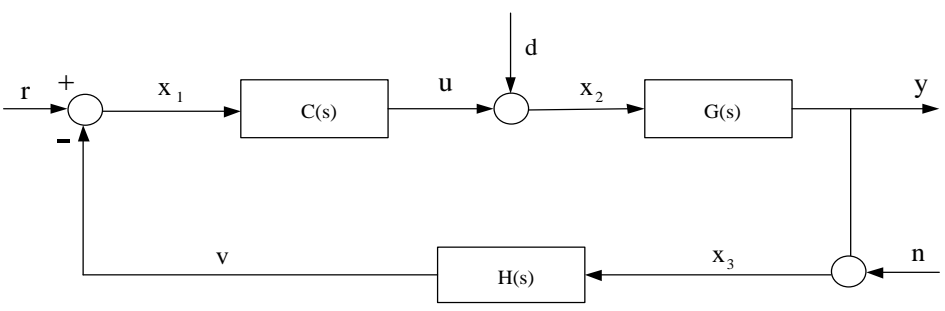

Gambar 3. Diagram Blok Sistem Umpan Balik Multivariabel [12]

Tabel 1. Keterangan Parameter Sistem Ekstiasi Generator

\begin{tabular}{|c|l|c|}
\hline Parameter & \multicolumn{1}{|c|}{ Keterangan } & Nilai \\
\hline $\mathrm{K}_{\mathrm{A}}$ & Konstanta penguatan amplifier & 10.0000 \\
\hline $\mathrm{T}_{\mathrm{A}}$ & Konstanta waktu amplifier & 0.1000 \\
\hline $\mathrm{K}_{\mathrm{E}}$ & Konstanta penguatan eksiter & 1.0000 \\
\hline $\mathrm{T}_{\mathrm{E}}$ & Konstanta waktu eksiter & 0.4000 \\
\hline $\mathrm{K}_{\mathrm{G}}$ & Konstanta penguatan generator & 1.0000 \\
\hline $\mathrm{T}_{\mathrm{G}}$ & Konstanta waktu generator & 1.0000 \\
\hline $\mathrm{K}_{\mathrm{s}}$ & Konstanta penguatan sensor & 1.0000 \\
\hline $\mathrm{T}_{\mathrm{s}}$ & Konstanta waktu sensor & 0.0100 \\
\hline
\end{tabular}

$$
\begin{aligned}
& \mathrm{G}(\mathrm{s}) \mathrm{H}(\mathrm{s})=\frac{10.0000}{0.0004 \mathrm{~s}^{4}+0.0454 \mathrm{~s}^{3}+0.555 \mathrm{~s}^{2}+1.5100 \mathrm{~s}+1.0000} \\
& \frac{\mathrm{V}_{\mathrm{t}}(\mathrm{s})}{\mathrm{V}_{\text {ref }}(\mathrm{s})}=\frac{0.1000 \mathrm{~s}+10.0000}{0.0004 \mathrm{~s}^{4}+0.0454 \mathrm{~s}^{3}+0.555 \mathrm{~s}^{2}+1.5100 \mathrm{~s}+11.0000}
\end{aligned}
$$

Tabel 2. Nilai Margin Penguatan dan Margin

\begin{tabular}{|l|c|}
\multicolumn{1}{c|}{ Fasa } \\
\hline Parameter & Nilai \\
\hline Margin Penguatan & $\begin{array}{c}1.7017 \\
(4.6176 \mathrm{~dB})\end{array}$ \\
\hline Frekuensi Margin Penguatan & $5.7672 \mathrm{rad} /$ detik \\
\hline Margin Fasa & $16.1030 \mathrm{derjat}$ \\
\hline Frekuensi Margin Fasa & $4.4027 \mathrm{rad} /$ detik \\
\hline
\end{tabular}

Hasil analisa kestabilan relatif untuk tanggapan tegangan sistem eksitasi generator tipe arus searah tanpa pengendali diperlihatkan pada Tabel 3.

Tabel 3. Nilai Indeks Kestabilan Relatif

\begin{tabular}{|c|c|}
\hline Kriteria & Nilai \\
\hline Nilai Puncak Resonansi & $3.8416(11.6900 \mathrm{~dB})$ \\
\hline
\end{tabular}

Hasil analisa kestabilan internal untuk tanggapan tegangan sistem eksitasi generator tipe arus serah tanpa pengendali diperlihatkan pada Tabel 4.
Tabel 4. Nilai Indeks Kestabilan Internal

\begin{tabular}{|c|c|}
\hline Parameter & Nilai \\
\hline Indeks Kestabilan & 0.0000 \\
\hline
\end{tabular}

Untuk hasil analisa kestabilan mutlak untuk tanggapan tegangan sistem eksitasi generator tipe arus serah dengan pengendali Proporsional (P) diperlihatkan pada Tabel 5.

Tabel 5. Nilai Margin Penguatan dan Margin

\begin{tabular}{|c|c|}
\hline Parameter & Nilai \\
\hline Margin Penguatan & $\begin{array}{c}4.2542 \\
(12.5760 \mathrm{~dB})\end{array}$ \\
\hline $\begin{array}{l}\text { Frekuensi Margin } \\
\text { Penguatan }\end{array}$ & $5.7672 \mathrm{rad} / \mathrm{detik}$ \\
\hline Margin Fasa & 50.5290 derjat \\
\hline Frekuensi Margin Fasa & $2.5320 \mathrm{rad} / \mathrm{detik}$ \\
\hline
\end{tabular}
Fasa

Hasil analisa kestabilan relatif untuk tanggapan tegangan sistem eksitasi generator 
tipe arus searah dengan pengendali Proporsional (P) diperlihatkan pada Tabel 6.

Tabel 6. Nilai Indeks Kestabilan Relatif

\begin{tabular}{|c|c|}
\hline Kriteria & Nilai \\
\hline Nilai Puncak Resonansi & $1.2136(1.6816 \mathrm{~dB})$ \\
\hline
\end{tabular}

Hasil analisa kestabilan internal untuk tanggapan tegangan sistem eksitasi generator tipe arus searah dengan pengendali Proporsional (P) diperlihatkan pada Tabel 7.

Tabel 7. Nilai Indeks Kestabilan Internal

\begin{tabular}{|c|c|}
\hline Parameter & Nilai \\
\hline Indeks Kestabilan & 0.0000 \\
\hline
\end{tabular}

Untuk hasil analisa kestabilan mutlak untuk tanggapan tegangan sistem eksitasi generator tipe arus serah dengan pengendali Proporsional Integral (PI) diperlihatkan pada Tabel 8.

Tabel 8. Nilai Margin Penguatan dan Margin

\begin{tabular}{|l|c|}
\multicolumn{1}{|c|}{ Pasa } \\
\hline Parameter & Nilai \\
\hline Margin Penguatan & $\begin{array}{c}4.3362 \\
(12.7420 \mathrm{~dB})\end{array}$ \\
\hline Frekuensi Margin Penguatan & $5.5005 \mathrm{rad} / \mathrm{detik}$ \\
\hline Margin Fasa & $49.0000 \mathrm{derjat}$ \\
\hline Frekuensi Margin Fasa & $2.3400 \mathrm{rad} / \mathrm{detik}$ \\
\hline
\end{tabular}

Hasil analisa kestabilan relatif untuk tanggapan tegangan sistem eksitasi generator tipe arus searah dengan pengendali Proporsional Integral (PI) diperlihatkan pada Tabel 9.

Tabel 9. Nilai Indeks Kestabilan Relatif

\begin{tabular}{|c|c|}
\hline Kriteria & Nilai \\
\hline Nilai Puncak Resonansi & $1.2391(1.8624 \mathrm{~dB})$ \\
\hline
\end{tabular}

Hasil analisa kestabilan internal untuk tanggapan tegangan sistem eksitasi generator tipe arus searah dengan pengendali Proporsional Integral (PI) diperlihatkan pada Tabel 10.

Tabel 10. Nilai Indeks Kestabilan Internal

\begin{tabular}{|c|c|}
\hline Parameter & Nilai \\
\hline Indeks Kestabilan & 0.0000 \\
\hline
\end{tabular}

Untuk hasil analisa kestabilan mutlak untuk tanggapan tegangan sistem eksitasi generator tipe arus serah dengan pengendali Proporsional Diferensial (PD) diperlihatkan pada Tabel 11.
Tabel 11. Nilai Margin Penguatan dan Margin Fasa

\begin{tabular}{|l|c|}
\hline \multicolumn{1}{|c|}{ Parameter } & Nilai \\
\hline Margin Penguatan & 16.6910 \\
& $(24.4490 \mathrm{~dB})$ \\
\hline Frekuensi Margin Penguatan & $30.5570 \mathrm{rad} / \mathrm{detik}$ \\
\hline Margin Fasa & $54.0000 \mathrm{derjat}$ \\
\hline Frekuensi Margin Fasa & $5.8500 \mathrm{rad} / \mathrm{detik}$ \\
\hline
\end{tabular}

Hasil analisa kestabilan relatif untuk tanggapan tegangan sistem eksitasi generator tipe arus searah dengan pengendali Proporsional Diferensial (PD) diperlihatkan pada Tabel 12.

Tabel 12. Nilai Indeks Kestabilan Relatif

\begin{tabular}{|c|c|}
\hline Kriteria & Nilai \\
\hline Nilai Puncak Resonansi & $1.1030(0.8516 \mathrm{~dB})$ \\
\hline
\end{tabular}

Hasil analisa kestabilan internal untuk tanggapan tegangan sistem eksitasi generator tipe arus searah dengan pengendali Proporsional Diferensial (PD) diperlihatkan pada Tabel 13.

Tabel 12. Nilai Indeks Kestabilan Internal

\begin{tabular}{|c|c|}
\hline Parameter & Nilai \\
\hline Indeks Kestabilan & 0.0000 \\
\hline
\end{tabular}

Untuk hasil analisa kestabilan mutlak untuk tanggapan tegangan sistem eksitasi generator tipe arus serah dengan pengendali Proporsional Integral Diferensial (PID) diperlihatkan pada Tabel 14.

Tabel 14. Nilai Margin Penguatan dan Margin

\begin{tabular}{|l|c|}
\multicolumn{1}{c|}{ Fasa } \\
\hline \multicolumn{1}{|c|}{ Parameter } & Nilai \\
\hline Margin Penguatan & $\begin{array}{c}8.9451 \\
(19.0320 \mathrm{~dB})\end{array}$ \\
\hline Frekuensi Margin Penguatan & $34.8620 \mathrm{rad} / \mathrm{detik}$ \\
\hline Margin Fasa & $50.0000 \mathrm{derjat}$ \\
\hline Frekuensi Margin Fasa & $10.0000 \mathrm{rad} /$ detik \\
\hline
\end{tabular}

Hasil analisa kestabilan relatif untuk tanggapan tegangan sistem eksitasi generator tipe arus searah dengan pengendali Proporsional Integral Diferensial (PID) diperlihatkan pada Tabel 15.

Tabel 15. Nilai Indeks Kestabilan Relatif

\begin{tabular}{|c|c|}
\hline Kriteria & Nilai \\
\hline Nilai Puncak Resonansi & $1.1792(1.4316 \mathrm{~dB})$ \\
\hline
\end{tabular}


Hasil analisa kestabilan internal untuk tanggapan tegangan sistem eksitasi generator tipe arus searah dengan pengendali Proporsional Integral Diferensial (PID) diperlihatkan pada Tabel 16.

Tabel 16. Nilai Indeks Kestabilan Internal

\begin{tabular}{|c|c|}
\hline Parameter & Nilai \\
\hline Indeks Kestabilan & 0.0000 \\
\hline
\end{tabular}

Hasil simulasi yang diperlihatkan pada Tabel 2 s/d Tabel 4 memperlihatkan bahwa tanggapan tegangan sistem eksitasi generator tipe arus searah tanpa pengendali bersifat tidak stabil mutlak dan tidak stabil relatif tetapi bersifat stabil internal. Hal ini dibuktikan dengan beberapa kriteria dimana untuk kestabilan mutlak ditunjukkan oleh nilai margin penguatan dan nilai margin fasa. Tanggapan tegagan sistem eksitasi generator tipe arus searah tanpa pengendali akan bersifat stabil mutlak jika mempuyai nilai margin penguatan besar dari $6.0000 \mathrm{~dB}$ dan nilai margin fasa berkisar antara $30.0000 \mathrm{~s} / \mathrm{d}$ 60.0000. Hasil perhitungan memperlihatkan bahwa tanggapan tegangan sistem eksitasi generator tipe arus searah tanpa pengendali bersifat tidak stabil mutlak dikarenakan nilai margin penguatan kurang dari $6.0000 \mathrm{~dB}$ sebesar $4.6176 \mathrm{~dB}$ dan nilai margin fasa tidak berada dalam rentang nilai 30.0000 derjat sampai 60.0000 derjat dengan nilai 16.1030 derjat.

Untuk kestabilan relatif ditunjukkan oleh nilai puncak resonansi. Tanggapan tegangan sistem eksitasi generator tipe arus searah tanpa pengendali akan bersifat stabil relatif jika mempuyai nilai puncak resonansi antara 1.1000 s/d 1.5000. Hasil perhitungan memperlihatkan bahwa tanggapan tegangan sistem eksitasi generator tipe arus searah tanpa pengendali bersifat tidak stabil relatif dikarenakan nilai puncak resonansi besar dari 1.5000 yaitu sebesar 3.8416. Untuk kestabilan internal ditunjukkan oleh nilai indeks kestabilan internal dimana nilai 0 menunjukkan sistem bersifat stabil internal dan nilai 1 menunjukkan sistem bersifat tidak stabil internal. Hasil perhitungan menunjukkan bahwa tanggapan tegangan sistem eksitasi generator tipe arus searah bersifat stabil internal dengan nilai indeks kestabilan internal sebesar 0 .
Untuk tanggapan tegangan sistem eksitasi generator tipe arus searah dengan pengendali Proporsional (P), Proporsional Integral (PI), Proporsional Diferensial (PD) dan pengendali Proporsional Integral Diferensial (PID) bersifat stabil mutlak. Untuk stabil mutlak dibuktikan dengan nilai margin penguatan yang besar dari $6 \mathrm{~dB}$ dan nilai margin fasa berkisar antara 30.0000 derjat sampai 60.0000 derjat. Untuk pengendali Proporsional (P), tanggapan tegangan sistem sistem eksitasi generator tipe arus searah mempuyai margin penguatan sebesar $12.5760 \mathrm{~dB}$ dan margin fasa 50.5290 derjat. Hasil perhitungan secara lengkap diperlihatkan pada Tabel 5. Untuk pengendali Proporsional Integral (PI), tanggapan tegangan sistem sistem eksitasi generator tipe arus searah mempuyai margin penguatan sebesar 12.7420 $\mathrm{dB}$ dan margin fasa 49.0000 derjat. Hasil perhitungan secara lengkap diperlihatkan pada Tabel 8. Untuk pengendali Proporsional Diferensial (PD), tanggapan tegangan sistem sistem eksitasi generator tipe arus searah mempuyai margin penguatan sebesar 24.4490 $\mathrm{dB}$ dan margin fasa 54.0000 derjat. Hasil perhitungan secara lengkap diperlihatkan pada Tabel 11. Untuk pengendali Proporsional Integral Diferensial (PID), tanggapan tegangan sistem sistem eksitasi generator tipe arus searah mempuyai margin penguatan sebesar 19.0320 $\mathrm{dB}$ dan margin fasa 50.0000 derjat. Hasil perhitungan secara lengkap diperlihatkan pada Tabel 14.

Selain bersifat stabil mutlak, tanggapan tegangan sistem eksitasi generator tipe arus searah dengan pengendali Proporsional (P), Proporsional Integral (PI), Proporsional Diferensial (PD) dan pengendali Proporsional Integral Diferensial (PID) bersifat stabil relatif. Untuk stabil relatif dibuktikan dengan nilai puncak resonansi dari tanggapan tegangan sistem eksitasi generator tipe arus searah mempuyai nilai antara $1.1000 \mathrm{~s} / \mathrm{d} 1.5000$. Untuk pengendali Proporsional (P) tanggapan tegangan sistem sistem eksitasi generator tipe arus searah mempuyai nilai puncak resonansi sebesar $1.2136(1.6816 \mathrm{~dB})$. Hasil perhitungan secara lengkap diperlihatkan pada Tabel 6 . Untuk pengendali Proporsional Integral (PI) tanggapan tegangan sistem sistem eksitasi generator tipe arus searah mempuyai nilai puncak resonansi sebesar $1.2391(1.8624 \mathrm{~dB})$. 
Hasil perhitungan secara lengkap diperlihatkan pada Tabel 9. Untuk pengendali Proporsional Diferensial (PD) tanggapan tegangan sistem sistem eksitasi generator tipe arus searah mempuyai nilai puncak resonansi sebesar $1.1030(0.8516 \mathrm{~dB})$. Hasil perhitungan secara lengkap diperlihatkan pada Tabel 12. Untuk pengendali Proporsional Integral Diferensial (PID) tanggapan tegangan sistem sistem eksitasi generator tipe arus searah mempuyai nilai puncak resonansi sebesar 1.1792 (1.4316 dB). Hasil perhitungan secara lengkap diperlihatkan pada Tabel 15.

Untuk kestabilan internal, tanggapan tegangan sistem eksitasi generator tipe arus searah dengan pengendali Proporsional (P), Proporsional Integral (PI), Proporsional Diferensial (PD) dan pengendali Proporsional Integral Diferensial (PID) bersifat stabil internal. Indikator kestabilan internal ditunjukkan oleh angka 0 jika sistem bersifat stabil internal dan angka 1 jika sistem bersifat tidak stabil internal. Hasil perhitungan secara lengkap untuk semua pengendali diperlihatkan pada Tabel 7, Tabel 10, Tabel 13 dan Tabel 16.

\section{KESIMPULAN}

Kesimpulan dari penelitian ini sebagai berikut

1. Tanggapan tegangan sistem eksitasi generator dengan pengendali Proporsional (P), Proporsional Integral (PI), Proporsional Diferensial (PD) dan Proporsional Integral Diferensial (PID) bersifat stabil mutlak, stabil relatif dan stabil internal. Untuk stabil mutlak dibuktikan dengan hasil perhitungan nilai margin penguatan yang besar dari $6.0000 \mathrm{~dB}$ dan nilai margin fasa antara 30.0000 derjat s/d 60.0000 derjat untuk setiap pengendali. Untuk stabil relatif ditunjukkan dengan hasil perhitungan nilai puncak resonansi yang berkisar antara $1.1000 \mathrm{~s} / \mathrm{d} 1.5000$ untuk semua pengendali. Untuk stabil internal dibuktikan dengan nilai indikator kestabilan internal yang bernilai 0 untuk semua pengendali.

2. Dengan pengendali Proporsional (P), tanggapan tegangan sistem eksitasi generator tipe arus searah mempuyai nilai margin penguatan sebesar 4.2542 (12.5760 dB), nilai margin fasa sebesar 50.5290 derjat, nilai puncak resonansi sebesar 1.2136 (1.6816) dan indeks kestabilan internal sebesar 0. Dengan pengendali Proporsional Integral (PI), tanggapan tegangan sistem eksitasi generator tipe arus searah mempuyai nilai margin penguatan sebesar 4.3362 $(12.7420 \mathrm{~dB})$, nilai margin fasa sebesar 49.0000 derjat, nilai puncak resonansi sebesar 1.2391 (1.8624 dB) dan dan indeks kestabilan internal sebesar 0. Dengan pengendali Proporsional Diferensial (PD), tanggapan tegangan sistem eksitasi generator tipe arus searah mempuyai nilai margin penguatan sebesar $16.6910(24.4490$ dB), nilai margin fasa sebesar 54.0000 derjat, nilai puncak resonansi sebesar 1.1030 $(0.8516 \mathrm{~dB})$ dan indeks kestabilan internal sebesar 0. Untuk pengendali Proporsional Integral Diferensial (PID), tanggapan tegangan sistem eksitasi generator tipe arus searah mempuyai nilai margin penguatan sebesar $8.9451(19.0320 \mathrm{~dB})$, nilai margin fasa sebesar 50.0000 derjat, nilai puncak resonansi sebesar $1.1792(1.4316 \mathrm{~dB})$ dan indeks kestabilan internal sebesar 0 .

\section{DAFTAR PUSTAKA}

[1] Graham, R., 1999. Power System Oscillations. Massachusetts: Kluwer Academic Publisher.

[2] Laksono, H. D. \& Yulianto, N. F., 2013. Evaluasi Kestabilan dan Kekokohan Tanggapan Tegangan Sistem Eksitasi Generator Dengan Metoda Penempatan Kutub Menggunakan Algoritma Ackerman - Gura. Konferensi Nasional $\mathrm{Ke}-7$ Forum Pendidikan Tinggi Teknik Elektro Indonesia (FORTEI), Padang 26 - 28 September 2013.

[3] Karnoto, M. Facta \& Aris T,2000. Perbandingan Pengaruh Sistem Eksitasi Konvensional dan Non Konvensional Terhadap Kestabilan Generator Untuk Meningkatkan Keandalan Sistem Kelistrikan, Proceedings, Seminar Sistem Tenaga Elektric I, Insitute Teknologi Bandung.

[4] Amin Setiadji, 2000, Implementasi Kontroler PID Pada AVR (Automatic Voltage Regulator) untuk Pengaturan Tegangan Eksitasi Generator Sinkron 3 Fasa, Politeknik Elektronika Negeri 
Surabaya - Institute Teknologi Sepuluh November.

[5] Endriyanto NW, 2001, Perencanaan Optimal Sistem Kontrol AVR (Automatic Voltage Regulator) Untuk Memperbaiki Kestabilan Tegangan Dengan Menggunakan Algoritma Genetik, Fakultas Teknik, Universitas Diponegoro, Semarang.

[6] Laksono, H. D. \& Rezki, S. O, 2012. Penerapan Sistem Kendali Kokoh Dengan Metoda H Pada Sistem Eksitasi Generator. Amplifier, 02(02).

[7] Sahib, M., 2015. A Novel Optimal PID Plus Second Oder Drivative Cntroller for AVR system. Engineering Science and Technology, 18(2), pp. 194 - 206.

[8] Saadat, H., 1999. Power System Analysis. Canada: McGraw Hill.

[9] Laksono, H. D, 2014. Sistem Kendali Dengan PID. Padang : Andalas University Press .

[10] Ogata, K., 2010. Modern Control Engineering. New York : Prentice Hall .

[11] Xue, D., Chen, Y. Q. \& Atherton, D. P., 2007. Linear Feedback Control: Analysis and Design With Matlab. Philadelphia : SIAM.

[12] Skogestad, S. \& Postlethwaite, I., 1996. Multivariable Feedback Control Analysis and Design. New York : McGraw Hill.

Heru Dibyo Laksono ST, MT, Menyelesaikan S1 di Jurusan Teknik Elektro Universitas Andalas (Unand) Padang tahun 2000 bidang Teknik Tenaga Listrik. Pendidikan S2 bidang Kendali dan Sistem diselesaikan di Institute Teknologi Bandung (ITB) tahun 2004. Masuk sebagai dosen Teknik Elektro Universitas Andalas sejak tahun 2005.

Mazues, ST, Terdaftar sebagai mahasiswa jurusan Teknik Elektro Fakultas Teknik Universitas Andalas pada tahun 2011 dengan bidang keahlian sistem tenaga listrik.

Wayu Diafridho A, ST, Terdaftar sebagai mahasiswa jurusan Teknik Elektro Fakultas Teknik Universitas Andalas pada tahun 2009. dengan bidang keahlian sistem tenaga listrik. Saat ini bekerja sebagai karyawan PT. PLN
(Persero) Area Padang Sidempuan Sumatera Utara. 